\title{
Evaluation of the PEAIII-LC3-KDEL3 Chimeric Protein of Entamoeba histolytica-Lectin as a Vaccine Candidate against Amebic Liver Abscess
}

\author{
Sandra L. Martínez-Hernández $\mathbb{D}^{1},{ }^{1}$ Viridiana M. Becerra-González, ${ }^{1}$ \\ Martín H. Muñoz-Ortega $\mathbb{D}^{2}{ }^{2}$ Víctor M. Loera-Muro, ${ }^{3}$ Manuel E. Ávila-Blanco $\mathbb{D}^{1}{ }^{1}$ \\ Marina N. Medina-Rosales $\mathbb{D}^{1}{ }^{1}$ and Javier Ventura-Juárez $\mathbb{D}^{1}$ \\ ${ }^{1}$ Departamento de Morfología, Centro de Ciencias Básicas, Universidad Autónoma de Aguascalientes, C. P. 20131., Aguascalientes, \\ Ags., Mexico \\ ${ }^{2}$ Departamento de Química, Centro de Ciencias Básicas, Universidad Autónoma de Aguascalientes, C. P. 20131., Aguascalientes, \\ Ags., Mexico \\ ${ }^{3}$ Departamento de Fisiología y Farmacología, Centro de Ciencias Básicas, Universidad Autónoma de Aguascalientes, C. P. 20131., \\ Aguascalientes, Ags., Mexico
}

Correspondence should be addressed to Javier Ventura-Juárez; jventur@correo.uaa.mx

Received 5 October 2020; Revised 24 February 2021; Accepted 6 March 2021; Published 22 March 2021

Academic Editor: Gabriela Santos-Gomes

Copyright (C) 2021 Sandra L. Martínez-Hernández et al. This is an open access article distributed under the Creative Commons Attribution License, which permits unrestricted use, distribution, and reproduction in any medium, provided the original work is properly cited.

\begin{abstract}
Entamoeba histolytica is an intestinal parasite that causes dysentery and amebic liver abscess. E. histolytica has the capability to invade host tissue by union of virulence factor Gal/GalNAc lectin; this molecule induces an adherence-inhibitory antibody response as well as to protect against amebic liver abscess (ALA). The present work showed the effect of the immunization with PESIII-LC3-KDEL3 recombinant protein. In vitro, this candidate vaccine inhibited adherence of E. histolytica trophozoites to HepG2 cell monolayer, avoiding the cytolysis, and in a hamster model, we observed a vaccine-induced protection against the damage to tissue liver and the inhibition of uncontrolled inflammation. PE $\Delta$ III-LC3-KDEL3 reduced the expression of TNF- $\alpha$, IL- $1 \beta$, and NF- $\kappa$ B in all immunized groups at 4 - and 7 -day postinfection. The levels of IL-10, FOXP3, and IFN- $\gamma$ were elevated at 7 days. The immunohistochemistry assay confirmed this result, revealing an elevated quantity of + IFN- $\gamma$ cells in the liver tissue. ALA formation in hamsters immunized was minimal, and few trophozoites were identified. Hence, immunization with PEAIII-LC3-KDEL3 herein prevented invasive amebiasis, avoided an acute proinflammatory response, and activated a protective response within a short time. Finally, this recombinant protein induced an increase of serum IgG.
\end{abstract}

\section{Introduction}

Entamoeba histolytica is an enteric protozoan parasite and the etiologic agent of amebiasis [1]. This disease is a worldwide health problem that affects an estimated 50 million people and causes over 100,000 deaths annually (primarily in developing countries) [2]. Children exposed to repeated infections can suffer malnourishment and the stunting of growth [3]. Whereas about $90 \%$ of amebic infections are asymptomatic, the other $10 \%$ display a spectrum of diseases: acute diarrhea, dysentery, amebic colitis, and amebic liver abscess (ALA); the latter is the most common extraintestinal manifestation of amebiasis [4], triggered by the capacity of $E$. histolytica to produce host cell death and a destructive inflammatory response [5]. Invasive amebiasis is treated with nitroimidazoles, which have toxic side effects and require complementary drugs to cure the infection in $40-60 \%$ of patients [6]. Despite the medical importance of this parasite, an effective vaccine to prevent amebiasis has not yet to become available. In the search for alternative treatments, the amebic galactose-binding lectin is today among the most commonly used antigens for carrying out exploratory assays. 
This complex protein is located on the surface of the parasite and consists of three subunits. The main component, the heavy subunit of $170 \mathrm{kDa}$, is one of the most immunogenic E. histolytica molecules [7], bearing a carbohydrate recognition domain rich in cysteines (LC3) [8].

In one of our previous studies, a chimeric vaccine (PEDIII-LC3-KDEL3) was elaborated that contained the Entamoeba histolytica LC3 fragment fused to domains I and II of exotoxin A of Pseudomonas aeruginosa ( $P$. aeruginosa) and the carboxy-terminal signal KDEL3 [9]; this chimeric molecule was evaluated in capability to raise antibodies in sera from animals immunized; it was detected a raised serum IgG at 2.03- to 2.1-fold greater concentration in immunized versus nonimmunized animals [9]. The aim of the present study was to evaluate the effect of PE $\Delta$ IIILC3-KDEL3 as a recombinant vaccine through analysis of its immunogenic activity (antibody production and modulation of inflammation), inhibition of cytotoxicity, and protection against the development of ALA.

\section{Materials and Methods}

2.1. Animals. Male golden hamsters (Mesocricetus auratus) weighing $80-100 \mathrm{~g}$ were used in this study. The animals were dewormed by ivermectin $5 \mathrm{mg}$ in $500 \mathrm{ml}$ of distilled water during the first week, after that, were maintained on standard diet with drinking water ad libitum. All animals received human care according to the guidelines of the Committee on Bioethics in the animal facilities of the Autonomous University of Aguascalientes, Aguascalientes, Mexico, which is based on the guidelines for animal research published by the National Institute of Health (National Research Council (US) Committee for the Update of the Guide for the Care and Use of Laboratory Animals, 2011) and the Mexican Official Norm: NOM-062-ZOO-1999 [10].

2.2. E. histolytica Culture. E. histolytica HM-1:IMSS trophozoites were grown axenically in TYI-S-33 [11]. Trophozoites were harvested at $72 \mathrm{~h}$ for use in all experiments.

2.3. Vaccine Antigen PEAIII-LC3-KDEL3. Recombinant vaccine was designed, purified, and analyzed by MartínezHernández et al. [9] and detected with a rabbit polyclonal anti-6X His tag antibody (Ab1187, Abcam, Cambridge, UK) and a rabbit polyclonal antibody monospecific to $E$. histolytica [12].

2.4. Immunization. Hamsters were divided into five groups $(n=5$ each), intact and sham as a control and three experimental. The former was healthy intact (no treatment nor infection) and sham, administered the vehicle (sterile PBS $1 \mathrm{x}, 100 \mu \mathrm{l})$ intramuscularly with a $0.40 \mathrm{~mm} \times 1 / 2$ inch needle. The three experimental groups were immunized intramuscularly with PEAIII-LC3-KDEL3 at doses of 50, 75, and $100 \mu \mathrm{g} /$ animal. The PE$\Delta \mathrm{III}-\mathrm{LC} 3-\mathrm{KDEL} 3$ and the vehicle were applied on days 1,7 , and 14 .

2.5. Experimental Hepatic Amebiasis. One week after the last immunization, amoebic liver abscesses were induced by direct hepatic inoculation as previously described [13]. On day 4 or 7 postinfection, the animals were anaesthetized with sodium pentobarbital and sacrificed. To evaluate the development of ALAs, liver samples were taken from all the animals and fixed with $4 \%$ paraformaldehyde processed in paraffin and submitted to hematoxylin and eosin (H\&E) staining. The tissue sections were stored in RNA later at $-81^{\circ} \mathrm{C}$ to await analysis.

2.6. Antibody Detection by ELISA. Serum was examined in vitro by ELISA for the identification of antibodies against E. histolytica elicited by treatment with PEAIII-LC3-KDEL3, by a slightly modified method [14], using E. histolytica membrane protein antigen [12], then, HRP-conjugated anti-hamster IgG antibody (H1643, SIGMA, San Luis Missouri, USA) (1:1000). After that, it was developed with orthophenylendiamine (Thermo Scientific 34005, MA USA) and read at $490 \mathrm{~nm}$ on an iMark-microplate-reader (Bio-Rad, Hercules, California, USA).

2.7. Cytotoxicity Assay. $2 \times 10^{4}$ trophozoites of E. histolytica were resuspended in TYI-S-33 medium; they were treated with dilutions $(1: 100)$ of immune serum (from the 50, 75, and $100 \mu \mathrm{g}$ groups) and sham serum at $37^{\circ} \mathrm{C}$ for $1 \mathrm{~h}$. For a positive control, trophozoites were left untreated. Simultaneous with the preincubation, $2 \times 10^{5}$ HepG2 cells were seeded in 24-well plates. Once they get confluence, trophozoites were added, and interaction between HepG2 cells and $E$. histolytica took place at $37^{\circ} \mathrm{C}$ for $2 \mathrm{~h}$. After that, wells were washed, fixed with $2 \%$ PFA, stained with $0.1 \%$ methylene blue in $10 \mathrm{mM}$ borate buffer for $15 \mathrm{~min}$, and finally washed 3 times. Subsequently, $0.1 \mathrm{M} \mathrm{HCl}$ was added, and each well was left at $37^{\circ} \mathrm{C}$ for $30 \mathrm{~min}$ to extract the stain. Absorbance was then read on a spectrometer at $655 \mathrm{~nm}\left(\mathrm{OD}_{655}\right)$. The percentage of monolayer destruction was calculated as follows: $\left[\left(\mathrm{OD}_{655}\right.\right.$ of control wells $)-\left(\mathrm{OD}_{655}\right.$ of experimental wells $) /(\mathrm{O}$ $\mathrm{D}_{655}$ of control wells)] $\times 100$.

2.8. Analysis of Cytokine Expression by RT-qPCR. The RNA extracted from the liver tissue from the immunized and nonimmunized animals was analyzed by RT-qPCR using specific primers for cytokine genes (Table 1). Total RNA was isolated from $100 \mathrm{mg}$ of liver tissue of control and experimental animals using the SV Total RNA Isolation System (Z3100, Promega, Madison, Wisconsin, USA), according to the manufacturer's protocol, then quantified with a Biodrop (Biochrom, Waterbeach Cambridge, United Kingdom) and stored at $-80^{\circ} \mathrm{C}$ until needed. Reverse transcription was performed with $1 \mu \mathrm{g}$ of total RNA and the GoScript Reverse Transcription System (A5001, Promega, Madison, Wisconsin, USA). Quantitative PCR was carried out with the Maxima SYBR Green/ROX qPCR Master Mix (2x) (K0221, Thermo Fisher Scientific, Waltham, Massachusetts, USA) in a StepOne System (Applied Biosystems, Foster City, California, USA), utilizing the following programming: $50^{\circ} \mathrm{C}$ for $2 \mathrm{~min}, 95^{\circ} \mathrm{C}$ for $3 \mathrm{~min}, 40$ cycles of $95^{\circ} \mathrm{C}$ for $45 \mathrm{sec}$, and $60^{\circ} \mathrm{C}$ for $35 \mathrm{sec}$. Oligonucleotides were designed to target the cytokine genes. Relative expression was normalized to that of $\beta$-actin, and the differences were determined using the $2^{-\Delta \Delta \mathrm{Cq}}$ relative method [15]. 
TAble 1: Primers used for RT-qPCR.

\begin{tabular}{|c|c|c|c|}
\hline \multirow{2}{*}{ Target } & \multicolumn{2}{|c|}{ Oligonucleotides } & \multirow{2}{*}{ Amplicon size } \\
\hline & Sense & Antisense & \\
\hline IL-10 & CAACTGCAGCGCTGT CATCGATTT & AGTGCCTTGAAGACG CCTTTCTCT & 175 \\
\hline IL- $1 \beta$ & TTT CCA CAG CGA TGA GAA TG & GCCACAATGACTGAC ACСAC & 217 \\
\hline IFN- $\gamma$ & CAGCAGCATGGAAAA ACTGA & GCTCGCCAGAATGTT TTTGT & 220 \\
\hline NF- $\kappa$ B & CAGGAGCCTCAAACC TGAAG & CGTCTGTG GAGAGA AGTCC & 174 \\
\hline FoxP3 & AAGTCCTGGCCACAT CTACG & GTCTGTGCCATT TCCCA CT & 246 \\
\hline TNF- $\alpha$ & ССTCCTGTCCGCCAT CAAG & CACTGAGTCGGTCAC CTTTC & 246 \\
\hline$\beta$-Actin & TGTCACCAACTGGGA CGATA & GGGGTGTTGAAGGTC TCAAA & 120 \\
\hline
\end{tabular}

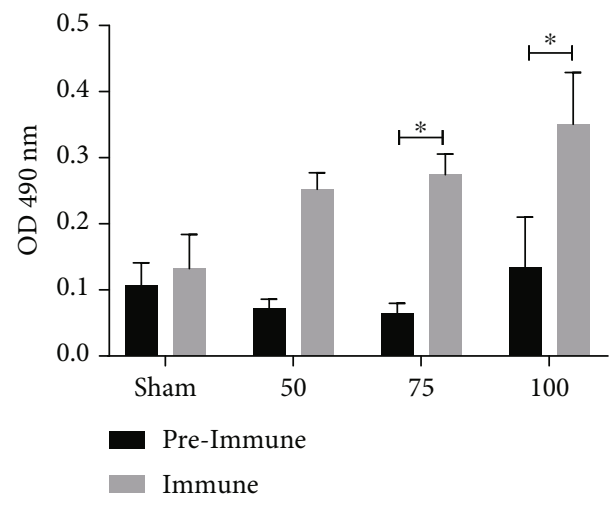

Figure 1: The PEAIII-LC3-KDEL3 vaccine induced IgG antibody production. Serum samples were evaluated by ELISA. Bars represent the mean \pm SEM of three independent assays. Statistical analysis was performed with one-way $\operatorname{ANOVA}^{*}(p<0.05)$.

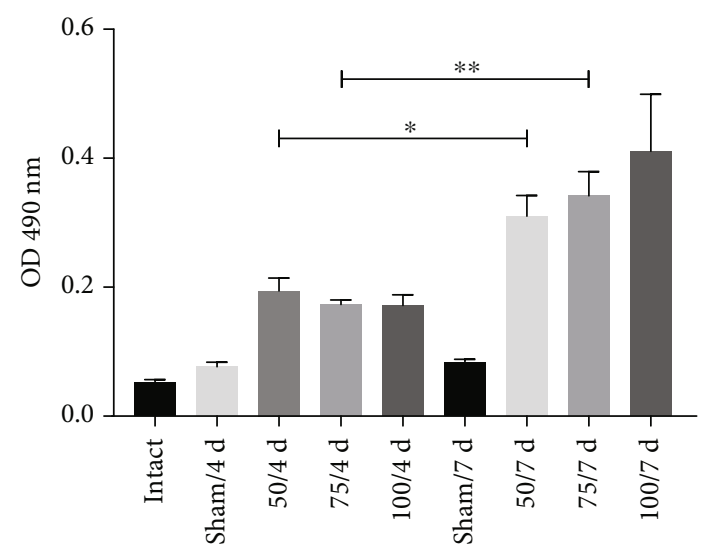

Figure 2: The antibody levels were elevated in the animals receiving the PEAIII-LC3-KDEL3 vaccine even in the postinfection period.

2.9. Immunohistochemistry. IFN- $\gamma$-positive cells and E. histolytica trophozoites were identified in liver tissue by immunohistochemistry as done by Ventura-Juárez et al. [16], Briefly, we used primary rabbit polyclonal anti-IFN- $\gamma$ antibody (500P32, Pepro-Tech, Cranbury, NJ, USA) diluted 1:200, $1 \mathrm{~h}$ at $37^{\circ} \mathrm{C}$. As a secondary antibody, Dako Envision system AP (IgG rabbit-mouse, K4065, DAKO, DNK) for $2 \mathrm{~h}$ and peroxidase activity were developed with diaminobenzidine for $5 \mathrm{~min}$. Images were captured and analyzed with the Image

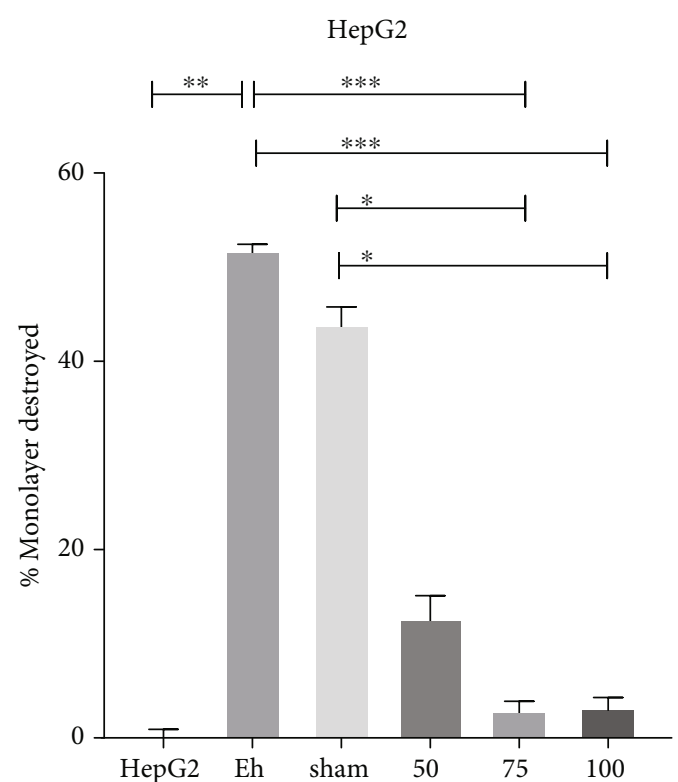

FIgURE 3: Inhibition of cytopathic effect of E. histolytica on HepG2 cells. Serum from the immunized groups inhibits destruction. Serum from sham animals generated a high percentage of destruction, similar to the positive control. HepG2 cells not exposed to E. histolytica represented the negative control. Data are expressed as the mean \pm SEM of three independent assays, no parametric test Dunn's post hoc. ${ }^{*} p<0.05 ;{ }^{* *} p<0.01 ;{ }^{* * *} p<$ 0.001 .

Pro Plus Software 4.5.1 (Media Cybernetics, Bethesda, Maryland, USA) in a Zeiss Axioscop 40/40L microscope (Zeiss, Oberkochen, DEU).

2.10. Statistical Analysis. Differences between groups were assessed with one-way analysis of variance (ANOVA), followed by Tukey's and Dunn's post hoc test, using GraphPad Prism version 8.0 for Windows (GraphPad Software, San Diego, California, USA). Data are expressed as the mean \pm SEM of the values from three independent experiments. Significance was considered at $p<0.05$.

\section{Results}

3.1. PEAIII-LC3-KDEL3 Increased Serum Antibody Levels. The levels of the specific antibodies elicited by the 


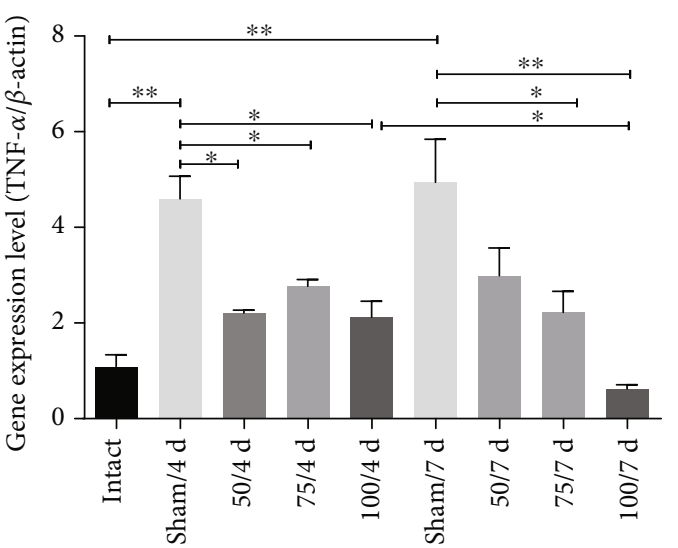

(a)

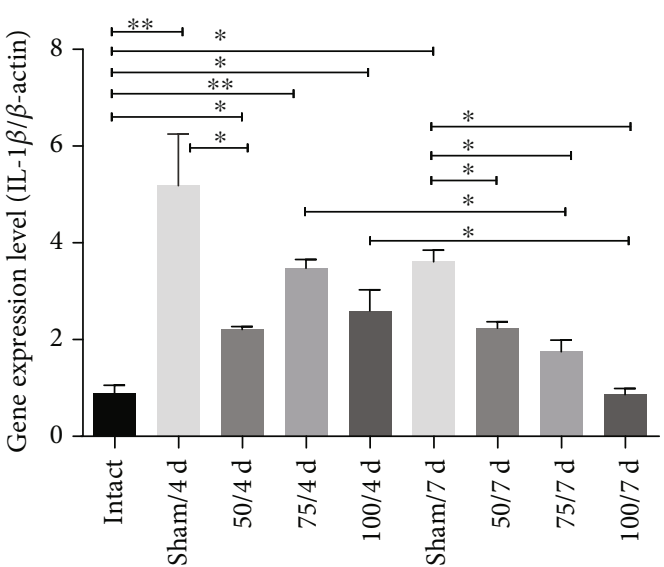

(b)

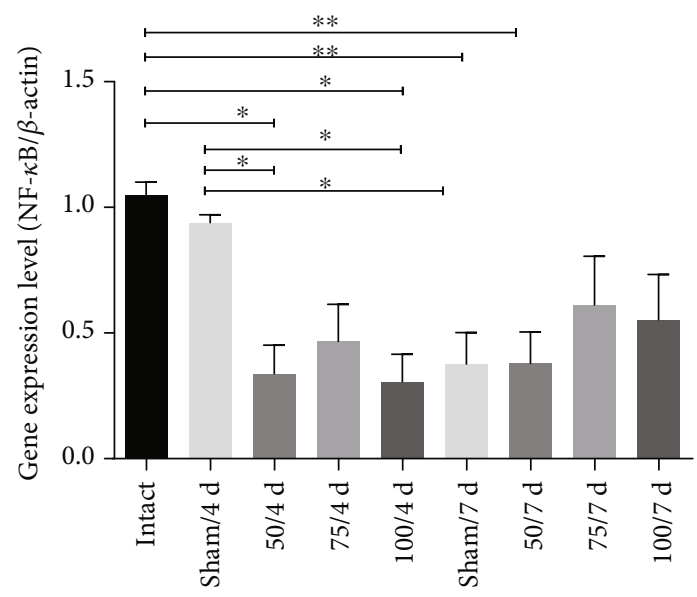

(c)

FIgURE 4: The vaccine reduced the expression of the proinflammatory genes. (a, b) TNF- $\alpha$ and IL-1 $\beta$ in all immunized hamsters at 4 - and 7 day postinfection were downregulated. (c) The NF- $\kappa$ B gene expression was also diminished in all immunized animals. Comparisons among groups: ${ }^{*} p<0.05$ and ${ }^{* *} p<0.01$.

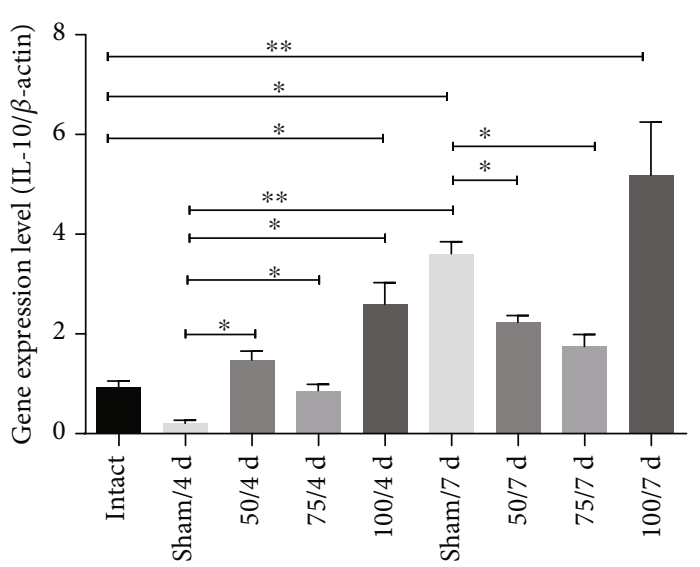

(a)

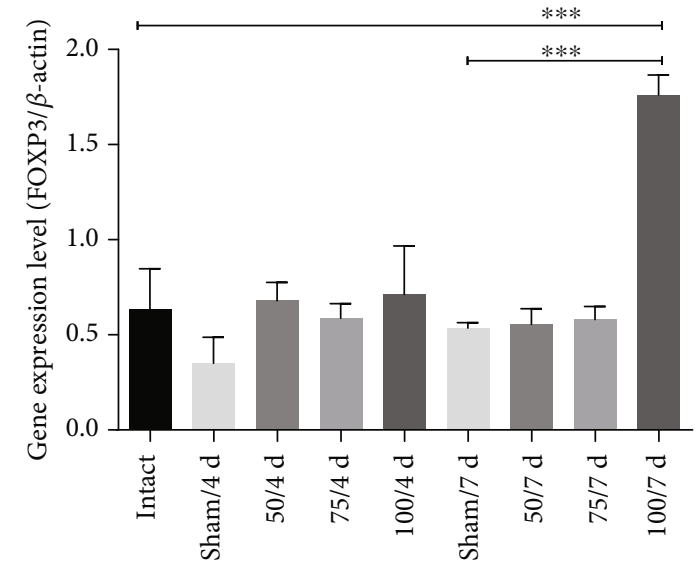

(b)

Figure 5: The PEAIII-LC3-KDEL3 vaccine upregulated IL-10 and FOXP3. (a, b) The $100 \mu \mathrm{g}$ concentration of the vaccine induced a greater IL-10 and FOXP3 gene expression at 7-day postinfection. (b) Comparisons between groups: ${ }^{*} p<0.05,{ }^{* *} p<0.01$, and ${ }^{* * *} p<0.001$. 
recombinant vaccine were determined in the serum from animals before and after immunization. All immunized hamsters developed a greater quantity of IgG antibodies than nonimmunized animals (Figure 1), although the difference was significant only for the 75 and $100 \mu$ groups. Immunized hamsters were infected 7-day postimmunization, then sacrificed at 4- and 7-day postinfection. Compared to the sham animals at day 7 postinfection, the antibody level in the 50 and $75 \mu \mathrm{g}$ groups showed a significant increase, while the level in the $100 \mu \mathrm{g}$ group was not significantly higher (Figure 2).

3.2. Immune Sera Inhibit E. histolytica Cytopathic Activity on HepG2 Cells. The ability of E. histolytica trophozoites to recognize and adhere to cells leads to cell death followed by phagocytosis [17]. Thus, HepG2 liver cells were herein exposed to trophozoites previously incubated for $1 \mathrm{~h}$ with the serum from immunized or nonimmunized animals. The virulent trophozoites without pretreatment and pretreated with serum from nonimmunized hamsters generated a high percentage of destruction of HepG2 cells $(51 \%$ and $44 \%$, respectively). The trophozoites pretreated with the serum from immunized animals inhibit destruction of the HepG2 cell monolayer, being $12.3 \%$ with $50 \mu \mathrm{g}$ and only $3.0 \%$ with both 75 and $100 \mu \mathrm{g}$ (Figure 3). This indicate that antibodies from vaccine-immunized hamsters recognized the LC3 fragment of trophozoites and interfered with the ability of the parasite to bind to and destroy the HepG2 cells.

3.3. Gene Expression of TNF- $\alpha, I L-1 \beta, I F N-\gamma$ NF- $\kappa B$, FOXP3, and IL-10 in Vaccinated Hamsters. Compared to the sham group, the gene expression for the proinflammatory cytokine TNF- $\alpha$ was significantly lower at 4 - and 7-day postinfection for the hamsters receiving 50, 75, and $100 \mu \mathrm{g}(p<0.05, p<$ 0.01 ) is important to realize that $100 \mu \mathrm{g}$ at 7 days was even more low than at 4 days (Figure $4(\mathrm{a})$ ). The IL- $1 \beta$ gene expression was diminished at 4 and 7 days in the $50 \mu \mathrm{g}$ group $(p<0.05)$; likewise, gene expression of this cytokine was low at 75 and $100 \mu \mathrm{g}$ at 7 days compared those to 4 days. Anterior results show a diminish timeline of the IL- $1 \beta$ gene expression (Figure $4(\mathrm{~b})$ ). To corroborate these results, the gene expression for nuclear factor kappa $\mathrm{B}(\mathrm{NF}-\kappa \mathrm{B})$ was also examined, finding it to be downregulated in all immunized hamsters $(p<0.05, p<0.01)$, except 75 and $100 \mu \mathrm{g}$ at 7 days (Figure 4(c)).

IL-10 participates in downregulating the inflammatory process. The gene expression of IL-10 increases at all doses at 4 days ( $p<0.05$ and $p<0.01$, respectively) compared to sham (Figure 5(a)). No significant difference existed among immunized groups (50, 75, and $100 \mu \mathrm{g}$ ) and intact hamsters, at 7 days only increase IL-10 gen in sham and $100 \mu \mathrm{g}$ (Figure 5(a)). Regarding FOXP3, the gene expression increased only in $100 \mu \mathrm{g}$ at 7 -day postinfection $(p<0.001)$ (Figure 5(b)). Additionally, the expression of INF- $\gamma$ gene in all immunized animals was significantly increased until 7-day postinfection $(p<0.05, p<0.01, p<$ 0.001) (Figure 6).

The immunohistochemistry assay confirmed this result, revealing an elevated quantity of $+\mathrm{IFN}-\gamma$ cells in liver tissue

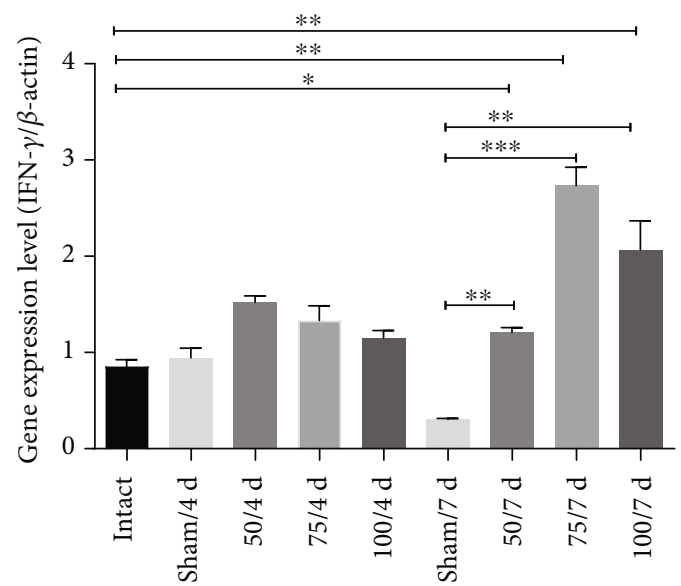

Figure 6: The PEAIII-LC3-KDEL3 vaccine promoted the expression of IFN- $\gamma$. The IFN- $\gamma$ gene expression in the 50,75 , and $100 \mu \mathrm{g}$ groups was only elevated at 7 -day postinfection. Comparisons between groups: ${ }^{*} p<0.05,{ }^{* *} p<0.01$, and ${ }^{* * *} p<$ 0.001 .

from animals immunized with $75 \mu \mathrm{g}$ (Figures $7(\mathrm{~g}), 7(\mathrm{~h}$ ), and $7(\mathrm{k}))$. As can be appreciated, the PE $\triangle$ III-LC3-KDEL3 vaccine had a downregulatory influence on the hamster immune response, which included anti-inflammatory effects.

3.4. Effects of the PEAIII-LC3-KDEL3 Vaccine on ALA Formation. Male hamsters were inoculated with $5 \times 10^{5}$ virulent $E$. histolytica trophozoites 7 days after vaccination. The liver tissue of the sham group showed characteristic ALA lesions: large, pale hemorrhagic zones located at the site of inoculation and were larger on 7 days than 4 days (Figures 8(a), (D) and 8(a), (C)). Compared to the sham hamsters, a considerable decrease in liver damage was found in all immunized groups; the liver tissue of the $50 \mu \mathrm{g}$ group displayed a small white lesion without hemorrhagic borders at 4 and 7 days (Figures 8(a), (E) and 8(a), (F)). The liver from inoculated with $75 \mu \mathrm{g}$ group exhibited a small lesion (at 4 days Figure 8(a), $(\mathrm{G})$ ) with a hemorrhagic area (at 7 days) (Figure $8(\mathrm{a}),(\mathrm{H})$ ). Surprisingly, evaluation of the liver tissue of the $100 \mu \mathrm{g}$ group revealed the absence of any lesion or hemorrhagic areas (at days 4 and 7; Figures 8(a), (I) and $8(\mathrm{a}),(\mathrm{J}))$. Histological analysis evidenced necrosis of the liver parenchyma (asterisks) and inflammatory infiltrate in the sham (arrows in Figure 8(b), (B)), and in 50 and $75 \mu \mathrm{g}$ groups, contrarily, there was a better architecture of the parenchyma without any tissue necrosis, although inflammatory infiltrate was detected (arrowheads, Figures 8(b), (C) and $8(\mathrm{~b}),(\mathrm{D}))$. Surprisingly, the architecture of the liver parenchyma was similar for the $100 \mu \mathrm{g}$ (Figure 8(b), (E)) and intact group (Figure 8(b), (A)), with no tissue disruption or inflammatory infiltrate.

3.5. Detection and Quantification of E. histolytica Trophozoites by Immunohistochemistry. We observed in the sham group the abundant trophozoites in liver parenchyma (arrowheads in Figures 9(c) and 9(d)); however, in hamsters immunized with $50 \mu \mathrm{g}$, fragments of trophozoites were 


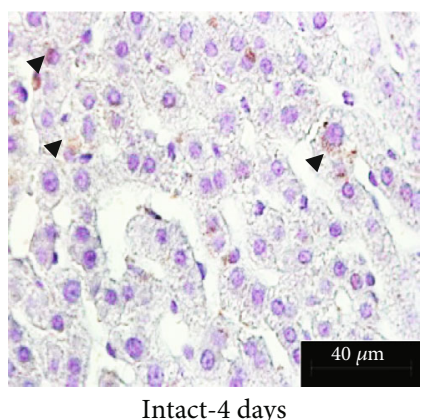

(a)

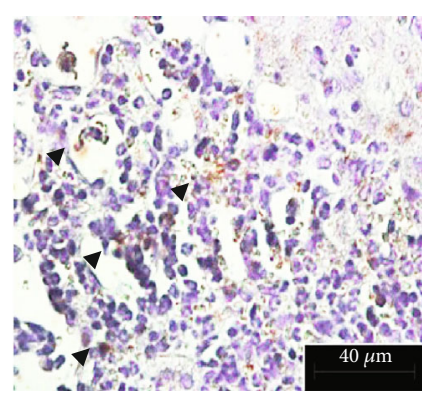

50-4 days

(e)

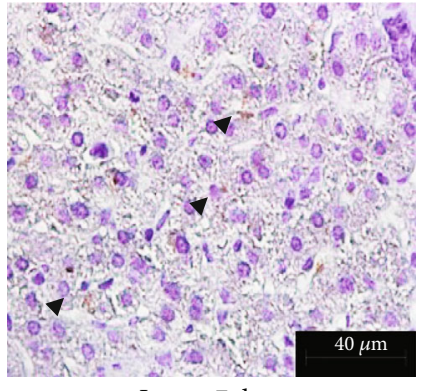

Intact-7 days

(b)

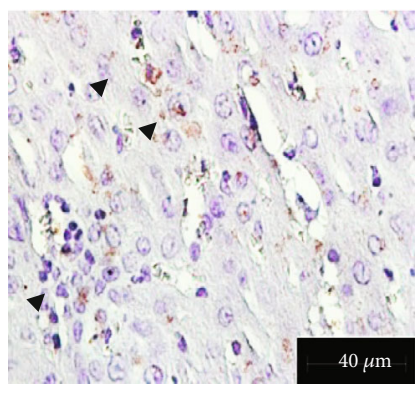

50-7 days

(f)

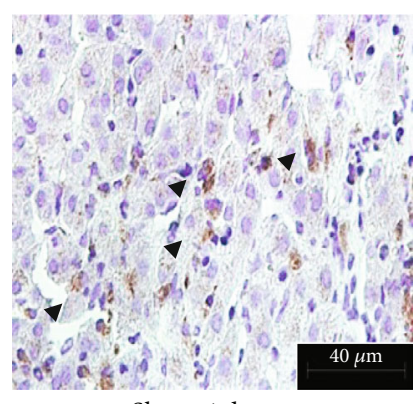

Sham-4 days

(c)

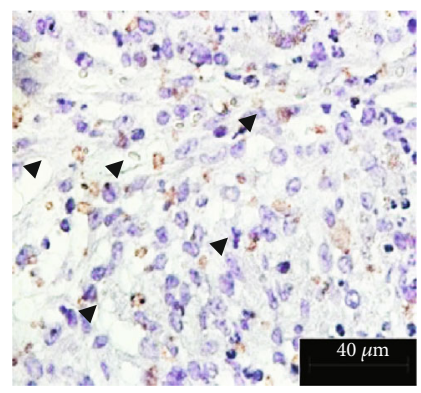

75-4 days

(g)

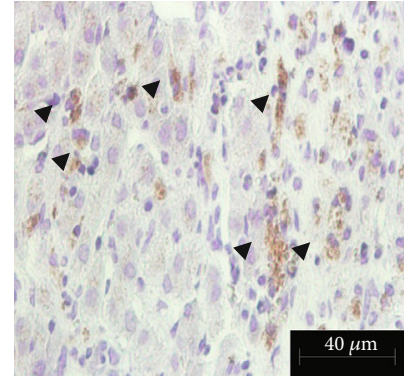

Sham-7 days

(d)

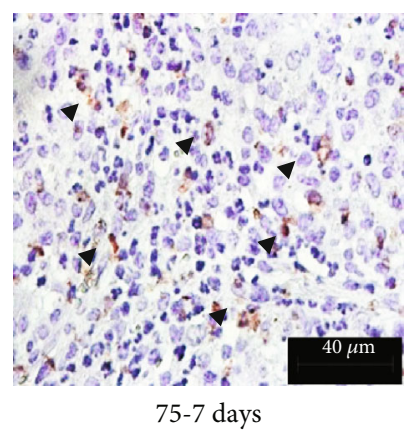

(h)

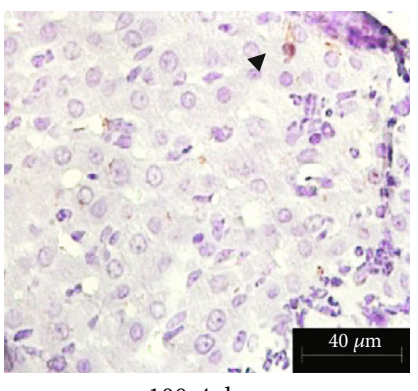

100-4 days

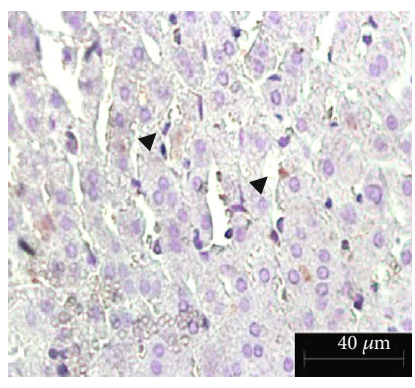

100-7 days

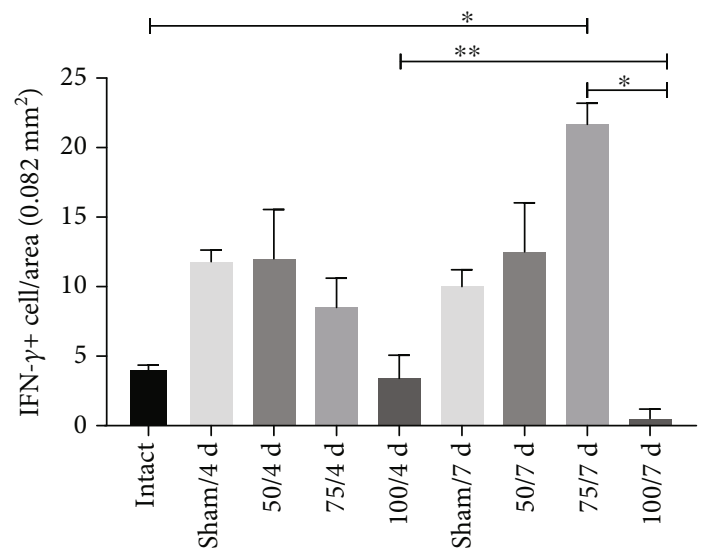

(k)

(i)

(j)

Figure 7: Immunohistochemical analysis of +IFN- $\gamma$ hepatic cells. Original magnification 400x. (a-j) Based on the immunohistochemistry assay, the quantity of $+\mathrm{IFN}-\gamma$ cells was determined in the liver tissue of hamsters (arrowhead). (k) The cells were abundant in $75 \mu \mathrm{g}$ group at 7 days.

identified (light brown, arrowheads in Figures 9(e) and 9(f)); in hamsters immunized with $75 \mu \mathrm{g}$, very few trophozoites invaded by inflammatory cells (arrowheads in Figures $9(\mathrm{~g})$ and $9(\mathrm{~h})$ ) can be identified; likewise, in hamsters immunized with $100 \mu \mathrm{g}$, at 4 days, small areas of inflammatory infiltrate are observed with few fragments of trophozoites (arrowheads in Figure 9(i)); finally, at 7 days, the tissue liver is seen healthy, and fragments of trophozoites are seen sporadically (arrowhead in Figure 9(j)).

\section{Discussion}

Amebiasis is a neglected disease that requires a solution, having widespread prevalence, and a significant annual mortality. The main treatment (nitroimidazole) for invasive amebiasis has serious adverse effects and in many cases requires the complement of additional medications. The vaccines elaborated to date induce only partial protection of the acquired immunity of the host, and the relative importance of mucosal, cellular, and humoral immunity in protection is still undetermined [18].

The amebic antigen most frequently investigated for the development of a vaccine is the galactose-binding lectin. Vaccines based on the native or recombinant form of the Gal/GalNAc lectin proteins are the most promising, with reports of success in protecting animals against intestinal amebiasis and ALA [7, 19-21]. Clinical trials will be required to validate its efficacy in humans [18]. 


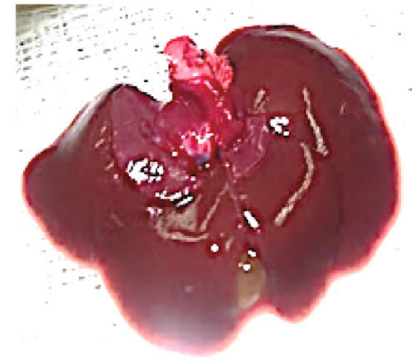

(a) Intact- 4 days

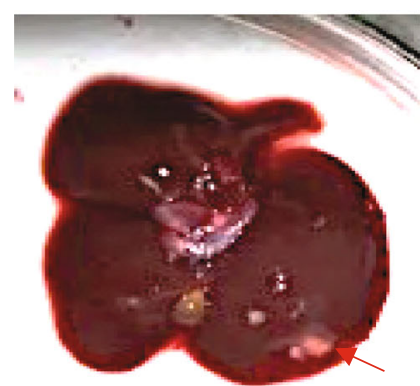

(e) 50-4 days

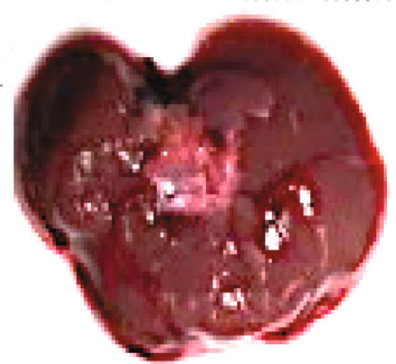

(b) Intact-7 days

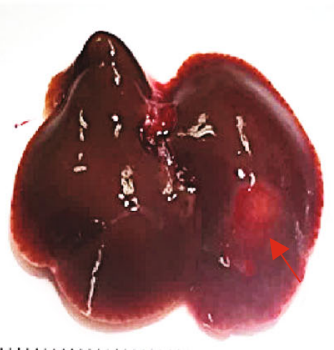

||||||||||||||||||||||

(f) 50-7 days

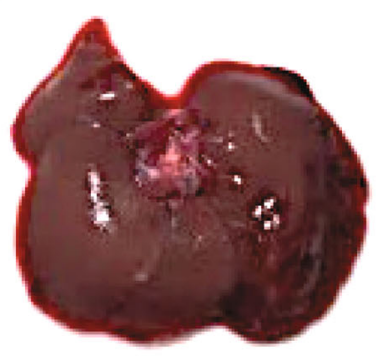

(i) 100-4 days

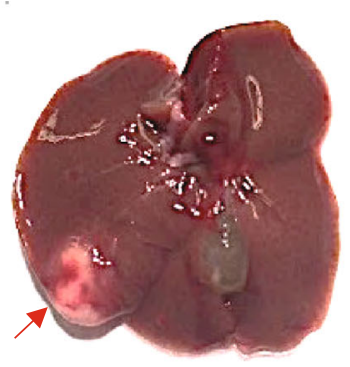

(c) Sham-4 days

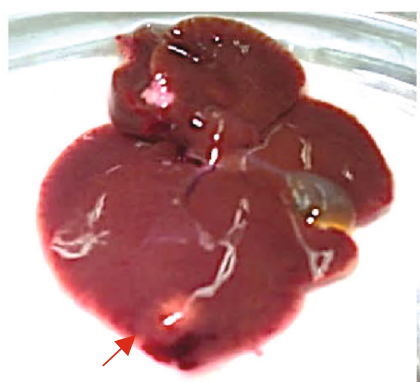

(g) 75-4 days

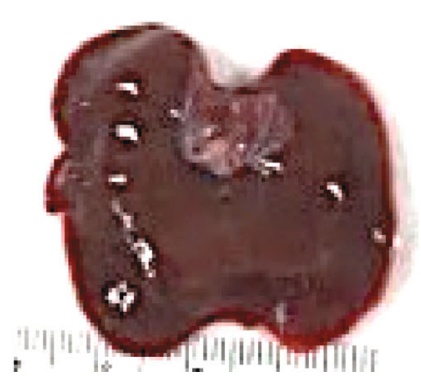

(j) 100-7 days

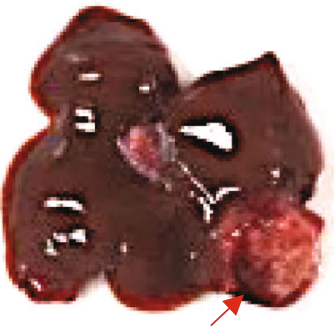

(d) Sham-7 days

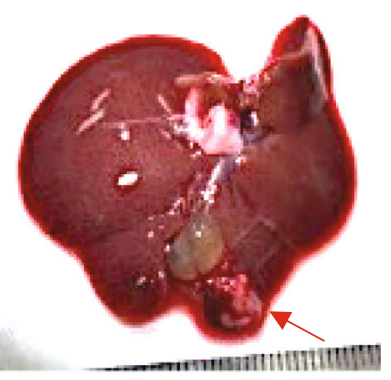

(h) 75-7 days

(a)

FIgure 8: Continued. 


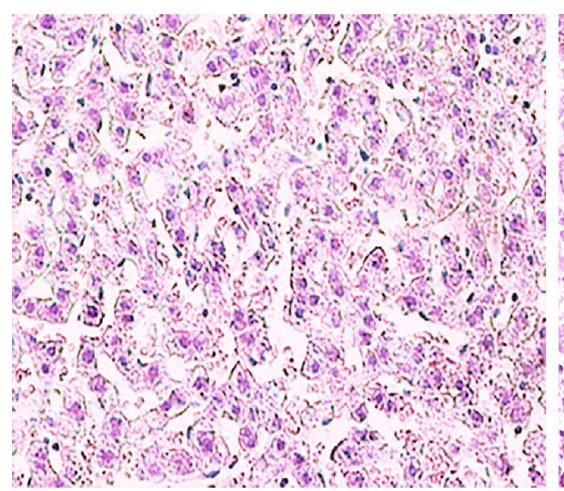

(a) Intact

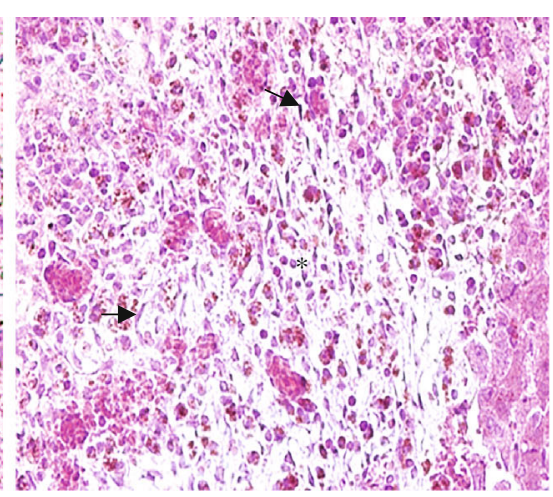

(b) Sham

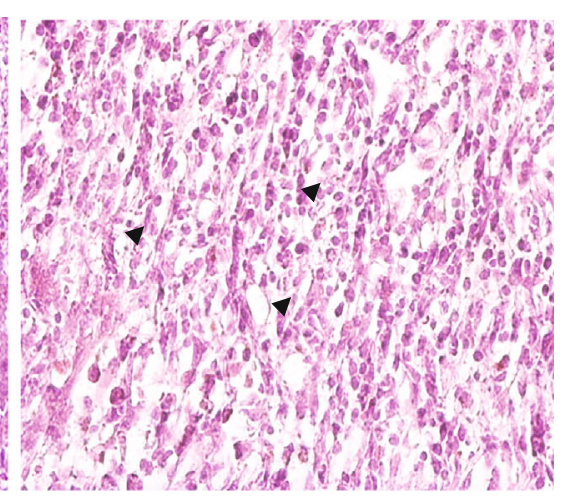

(c) 50

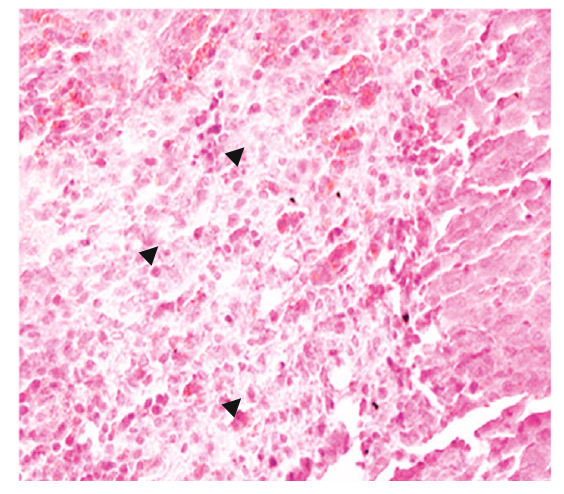

(d) 75

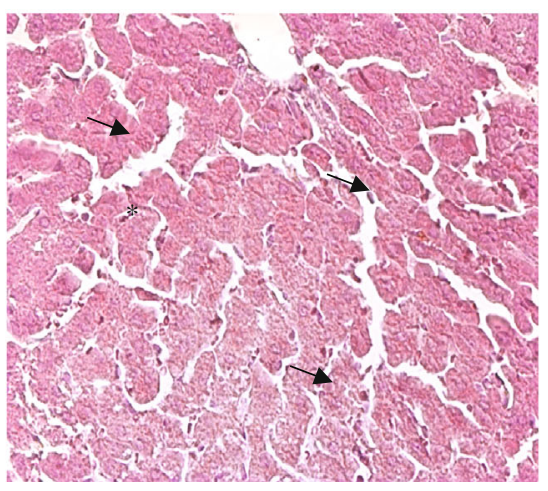

(e) 100

(b)

Figure 8: (a) Macroscopic analysis of amebic liver abscess formation. (A, B) No abscesses were detected in the liver of uninfected hamsters. (C, D) The liver of the sham group showed the characteristic ALA lesions. (E, F) The $50 \mu \mathrm{g}$ group exhibited smaller lesions on day 7 than day 4 than sham. (G, H) A single small lesion is seen in the $75 \mu$ g group (arrows). (I, J) No lesion was detected in the liver of the $100 \mu \mathrm{g}$ group. (b) Light microscopy of paraffin histological technique of amoebic liver abscess. Original magnification 400x. (A) In the intact hamsters, normal architecture was found in the liver tissue. (B, C) In two of the infected groups, sham and vaccinated with $50 \mu \mathrm{g}$, a necrotic area was observed in the liver parenchyma, accompanied by inflammatory infiltrate (arrows, asterisk). (D) In the $75 \mu \mathrm{g}$ group, the parenchyma displayed no tissue necrosis (arrowhead). (E) In the $100 \mu \mathrm{g}$ group, the parenchyma was similar to the intact animals, and there was no tissue necrosis or inflammation (arrows, cross).

The aim of the present study was to test a recombinant vaccine based on the Gal-lectin antigen in a hamster model. This vaccine has better immunostimulatory characteristics $[22,23]$. The most important findings of the current contribution in regard to the PEAIII-LC3-KDEL3 vaccine are its effective liver tissue protection and ability to inhibit important amebic virulent functions. The latter is related to the stimulation of antibody production and the inhibition of the inflammatory response.

In response to the vaccine, the animals generated IgGtype antibodies in serum. The lectin Gal/GalNAc is by itself a highly antigenic molecule [24] that promotes the production of specific antibodies against E. histolytica in gerbil and mouse models of amebiasis [16]. The antibodies elicited by the vaccine were able to inhibit the cytotoxicity of virulent E. histolytica on HepG2 cells. This effect is especially important because the adhesion of trophozoites to host cells is a prerequisite for their capacity to destroy cells $[17,25]$. A hallmark of E. histolytica-induced damage to host tissue is the presence of excessive inflammation, which is triggered by the activation of transcriptional factors that elicit the production and release inflammatory mediators [26-28]. For instance, TNF- $\alpha$ and IL- $1 \beta$ stimulate an inflammatory response and contribute to tissue damage $[29,30]$. Additionally, TNF- $\alpha$ foments the migration of trophozoites [31]. In the current study, all animals immunized with PEAIII-LC3KDEL3 showed an attenuation of inflammatory factors in the liver microenvironment.

PEAIII-LC3-KDEL3 herein promoted IL-10 cytokine gene expression, which may contribute to protection. For example, this cytokine with powerful anti-inflammatory properties [32] is related to the resistance of animals to an invasive E. histolytica infection by avoiding damage to host tissue and maintaining tissue homeostasis [33, 34] limiting like this an excessive inflammation, thus protecting the hamsters from ALA formation. Accordingly, there was an increase for FOXP3 in immunized groups; as a consequence, it was a decrease for NF- $\kappa \mathrm{B}$.

On the other hand, some studies focusing on animal models and on human infection have established that 


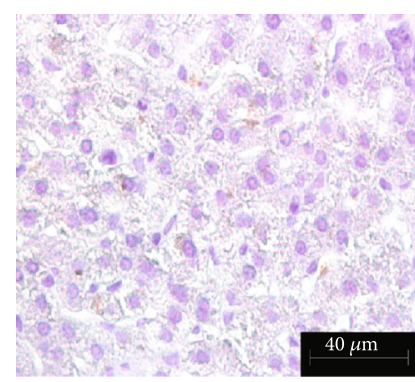

Intact-4 days

(a)

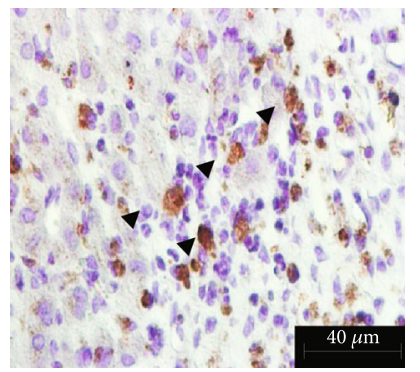

Sham-4 days

(c)

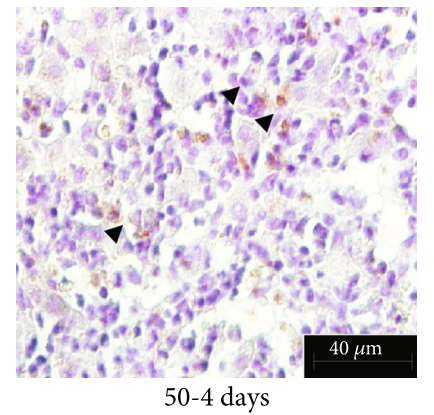

(e)

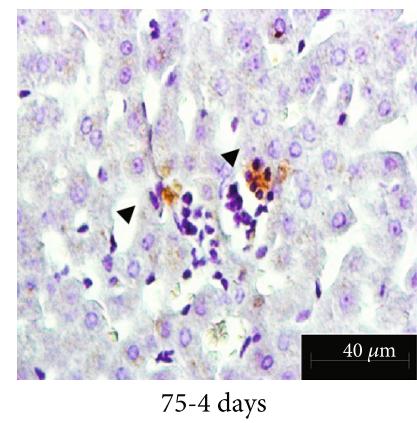

(g)

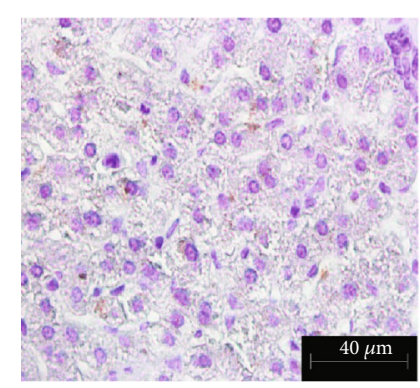

Intact-7 days

(b)

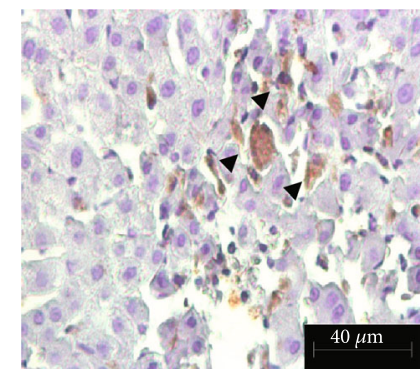

Sham-7 days

(d)

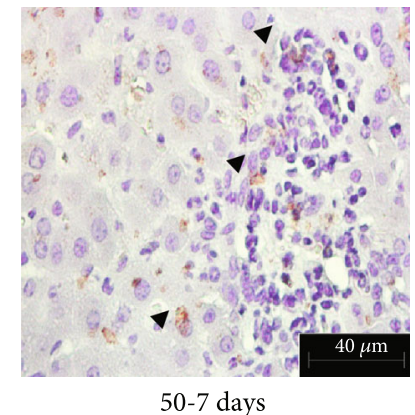

(f)

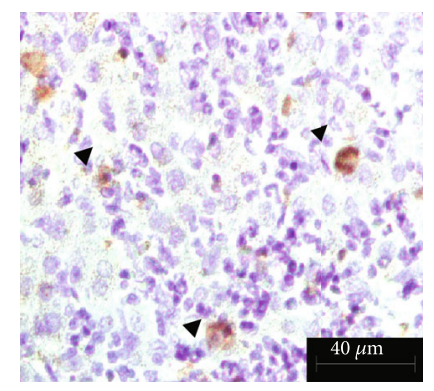

75-7 days

(h)

Figure 9: Continued. 


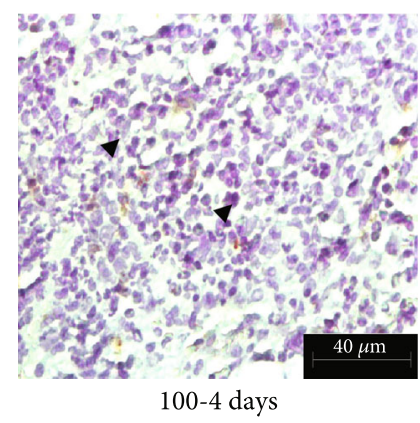

(i)

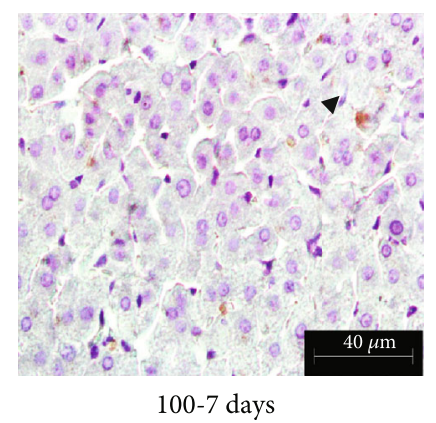

(j)

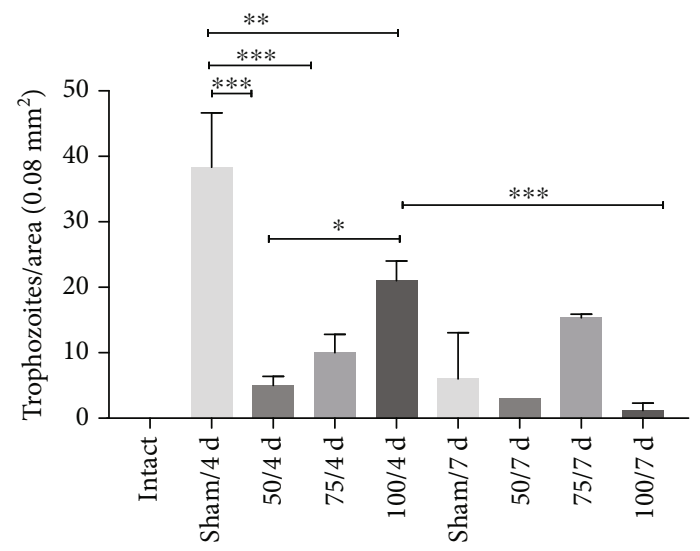

(k)

Figure 9: Immunohistochemistry detection for E. histolytica trophozoites. Original magnification 400x. (c, d) Trophozoites and their fragments $(e-j)$ can see by the light brown color (arrowheads). The number of trophozoites was lower as increment the vaccine dose (e-j). (k) Graphical expression of quantity of E. histolytica trophozoites per tissue area $\left({ }^{*} p<0.05,{ }^{* *} p<0.01,{ }^{* * *} p<0.001\right)$.

amebiasis vaccines require a Th1 response [35]. Our results evidence an elevated expression of the IFN- $\gamma$ gene at the last period analyzed (at 7 days). IFN- $\gamma$ reportedly plays an important role in the host defense against $E$. histolytica $[36,37]$. One mechanism described in the literature is its activation of macrophages to produce reactive oxygen species (ROS) and reactive nitrogen species (RNS), which are cytotoxic to the parasite [38].

The ALA lesion induced in the animals was minimal. This panorama was also observed by Meneses-Ruiz [39], who described "sterile protection against ALA." The protection provided by the PEAIII-LC3-KDEL3 vaccine likely stems in part from its upregulation of IFN- $\gamma$, leading to an effective Th1 response against $E$. histolytica and the downregulation of the immune response through IL-10 and FOXP3.

This vaccine represents a successful example of a recombinant protein that utilizes domains of a bacterial toxin for the development a potent vaccine against $E$. histolytica [16, 40]. PEAIII-LC3-KDEL3 was presently administered in the absence of adjuvants, unlike the majority of studies on vaccine candidate proteins, including serine-rich protein (SREHP) [41], Gal/GalNac lectin [19], $112 \mathrm{kDa}$ [42], and peroxyredoxin [43]. Many authors have reported that adjuvants induce focal necrosis and a granulomatous inflammatory response, with the predominance of macrophages at the injection site (elicited by Freund's adjuvant) $[44,45]$.

\section{Conclusions}

PEAIII-LC3-KDEL3 recombinant protein prevent invasive amebiasis, inhibiting an excessive inflammatory response and activate a protective response in a short time.

Further research is underway to attain a more in-depth understanding of the immunological activity of this vaccine with the aim of allowing for its use in clinical trials.

\section{Data Availability}

The data used to support the findings of this study were supplied by Sandra Luz Martínez-Hernández under license and so cannot be made freely available. Requests for access to these data should be made to Sandra Luz Martínez-Hernández, email: lilith3050@hotmail.com. Previously reported data for design amoebic recombinant vaccine were used to support this study and are available at DOI 10.1007/s10529017-2341-2. These prior studies are cited at relevant places within the text as references [\# 9].

\section{Conflicts of Interest}

The authors declare that there is no conflict of interest regarding the publication of this paper. 


\section{Authors' Contributions}

SLMH designed, obtained, and evaluated the PEAIII-LC3KDEL3 vaccine. VMBG developed the histological technique in the liver tissues. MHMO contributed with the analysis of RT-qPCR. VMLM and MEAB contributed with the microscopy analysis and the statistical analysis of the data. MNRM contributed with the maintenance of trophozoites and HepG2 cells. JVJ contributed to the conception, design, writing, and revision of the manuscript. All of the authors have approved the final manuscript.

\section{Acknowledgments}

The present study was financed by grant PIBB16-2 from the Universidad Autónoma de Aguascalientes and Grant 286184 from the Consejo Nacional de Ciencia y Tecnología (CONACYT). Sandra Luz Martínez-Hernández was granted a fellowship by CONACYT (244835) as part of the doctorate program in Biological Sciences in the Universidad Autónoma de Aguascalientes.

\section{References}

[1] C. Ximénez, R. Cerritos, L. Rojas et al., "Human amebiasis: breaking the paradigm?", International Journal of Environmental Research and Public Health, vol. 7, no. 3, pp. 11051120, 2010.

[2] WHO, "A moebiasis," Releve Epidemiologique, vol. 72, no. 14, pp. 97-99, 1997.

[3] R. B. Sack, R. Haque, D. Mondal, W. A. Petri, and B. D. Kirkpatrick, "Attribution of malnutrition to cause-specific diarrheal illness: evidence from a prospective study of preschool children in Mirpur, Dhaka, Bangladesh," The American Journal of Tropical Medicine and Hygiene, vol. 80, no. 5, pp. 824-826, 2009.

[4] R. Haque, C. D. Huston, M. Hughes, E. Houpt, and W. A. Petri Jr., "Amoebiasis: review article," The New England Journal of Medicine, vol. 348, no. 16, pp. 1565-1573, 2003.

[5] S. Ghosh, J. Padalia, and S. Moonah, "Tissue destruction caused by Entamoeba histolytica parasite: cell death, inflammation, invasion, and the gut microbiome," Current Clinical Microbiology Reports, vol. 6, no. 1, pp. 51-57, 2019.

[6] W. A. Petri Jr., "Therapy of intestinal protozoa," Trends in Parasitology, vol. 19, no. 11, pp. 523-526, 2003.

[7] H. Lotter, T. Zhang, and K. B. Seydel, "Identification of an epitope on the Entamoeba histolytica $170-\mathrm{kDa}$ lectin conferring antibody-mediated protection against invasive amebiasis," Journal of Experimental Medicine, vol. 185, no. 10, pp. 17931801, 1997.

[8] B. J. Mann, B. E. Torian, T. S. Vedvick, and W. A. Petri, "Sequence of a cysteine-rich galactose-specific lectin of Entamoeba histolytica," Proceedings of the National Academy of Science of the United States of America, vol. 88, no. 8, pp. 3248-3252, 1991.

[9] S. L. Martínez-Hernández, D. Cervantes-García, M. H. Muñoz-Ortega et al., "An anti-amoebic vaccine: generation of the recombinant antigen LC3 from Entamoeba histolytica linked to mutated exotoxin A (PEAIII) via the Pichia pastoris system," Biotechnology Letters, vol. 39, no. 8, pp. 1149-1157, 2017.
[10] L. I. O. Muñoz, Norma Oficial Mexicana NOM-062-ZOO1999, especificaciones técnicas, Diario Oficial De La Federacion, Mexico, 2007.

[11] L. S. Diamond, D. R. Harlow, and C. C. Cunnick, "A new medium for the axenic cultivation of Entamoeba histolytica and other Entamoeba," Transaction of The Royal Society of Tropical Medicine and Hygiene, vol. 72, no. 4, pp. 431-432, 1978.

[12] J. Ventura-Juárez, R. Campos-Rodríguez, and V. Tsutsumi, "Early interactions of Entamoeba histolytica trophozoites with parenchymal and inflammatory cells in the hamster liver: an immunocytochemical study," Canadian Journal of Microbiology, vol. 48, no. 2, pp. 123-131, 2002.

[13] C. P. Ivory, K. Keller, and K. Chadee, "CpG-oligodeoxynucleotide is a potent adjuvant with an Entamoeba histolytica Gal-inhibitable lectin vaccine against amoebic liver abscess in gerbils," Infection and Immunity, vol. 74, no. 1, pp. 528-536, 2006.

[14] P. K. Vaz, C. A. Hartley, and G. F. Browing, "Marsupial and monotreme serum immunoglobulin binding by proteins $\mathrm{A}$, $\mathrm{G}$ and $\mathrm{L}$ and anti-kangaroo antibody," Journal of Immunological Methods, vol. 427, pp. 94-99, 2015.

[15] K. J. Livak and T. D. Schmittgen, "Analysis of relative gene expression data using real-time quantitative PCR and the $2^{-\Delta \Delta C}$ method," Methods, vol. 25, no. 4, pp. 402-408, 2001.

[16] S. L. Stanleyr Jr., "Progress towards development of a vaccine for amebiasis," Clinical Microbiology Reviews, vol. 10, no. 4, pp. 637-649, 1997.

[17] U. Katz, S. Ankri, T. Stolarsky, Y. Nuchamowitz, and D. Mirelman, "Entamoeba histolytica expressing a dominant negative $\mathrm{N}$-truncated light subunit of its gal-lectin are less virulent," Molecular Biology of the Cell, vol. 13, no. 12, pp. 42564265, 2002.

[18] D. T. Shirley, K. Watanabe, and S. Moonah, "Significance of amebiasis: 10 reasons why neglecting amebiasis might come back to bite us in the gut," PLoS Neglected Tropical Diseases, vol. 13, no. 11, article e0007744, 2019.

[19] W. A. Petri Jr. and J. I. Ravdin, "Protection of gerbils from amebic liver abscess by immunization with the galactosespecific adherence lectin of Entamoeba histolytica," Infection and Immunity, vol. 59, no. 1, pp. 97-101, 1991.

[20] E. C. Roncolato, J. E. Teixeira, J. E. Barbosa, L. N. Zambelli Ramalho, and C. D. Huston, "Immunization with the Entamoeba histolytica surface metalloprotease EhMSP-1 protects hamsters from amebic liver abscess," Infection and Immunity, vol. 83, no. 2, pp. 713-720, 2015.

[21] Y. Jinno, M. Ogata, V. K. Chaudhary et al., "Domain II mutants of pseudomonas exotoxin deficient in translocation," The Journal of Biological Chemestry, vol. 264, no. 27, pp. 15953-15959, 1989.

[22] J. Fominaya and W. Wels, “Target cell-specific DNA transfer mediated by a chimeric multidomain protein: novel nonviral gene delivery system," The Journal of Biological Chemestry, vol. 271, no. 18, pp. 10560-10568, 1996.

[23] C. W. Liao, C. A. Chen, C. N. Lee et al., "Fusion protein vaccine by domains of bacterial exotoxin linked with a tumor antigen generates potent immunologic responses and antitumor effects," Cancer Research, vol. 65, no. 19, pp. 9089-9098, 2005.

[24] W. A. Petri Jr., J. Broman, G. Healy, T. Quinn, and J. I. Ravdin, "Antigenic stability and immunodominance of the Gal/GalNAc adherence lectin of Entamoeba Histolytica," The 
American Journal of the Medical Sciences, vol. 297, no. 3, pp. 163-165, 1989.

[25] K. S. Ralston and W. A. Petri Jr., "Tissue destruction and invasion by Entamoeba histolytica," Trends in Parasitology, vol. 27, no. 6, pp. 254-263, 2011.

[26] K. B. Seydel, E. Li, P. Swanson, and S. L. Stanley Jr., "Human intestinal epithelial cells produce proinflammatory cytokines in response to infection in a SCID mouse-human intestinal xenograft model of amebiasis," Infection and Immunity, vol. 65, no. 5, pp. 1631-1639, 1997.

[27] K. B. Seydel, E. Li, Z. Zhang, and S. L. Stanley Jr., "Epithelial cell-initiated inflammation plays a crucial role in early tissue damage in amebic infection of human intestine," Gastroenterology, vol. 115, no. 6, pp. 1446-1453, 1998.

[28] S. Blazquez, M. C. Rigothier, M. Huerre, and N. Guillen, "Initiation of inflammation and cell death during liver abscess formation by Entamoeba histolytica depends on activity of the galactose/N-acetyl-d- galactosamine lectin," International Journal of Parasitology, vol. 37, no. 3-4, pp. 425-433, 2007.

[29] S. N. Moonah, N. M. Jiang, and W. A. Petri Jr., "Host immune response to intestinal amebiasis," PLoS Pathogens, vol. 9, no. 8, article e10034899:8, 2013.

[30] Z. Zhang, S. Mahajan, X. Zhang, and S. L. Stanley Jr., "Tumor necrosis factor alpha is a key mediator of gut inflammation seen in amebic colitis in human intestine in the SCID mouse-human intestinal xenograft model of disease," Infection and Immunity, vol. 71, no. 9, pp. 5355-5359, 2003.

[31] S. Blazquez, C. Zimmer, G. Guigon, J. C. Olivo-Marin, N. Guillén, and E. Labruyère, "Human tumor necrosis factor is a chemoattractant for the parasite Entamoeba histolytica," Infection and Immunity, vol. 74, no. 2, pp. 1407-1411, 2006.

[32] R. Sabat, G. Grütz, K. Warszawska et al., "Biology of interleukin-10," Cytokine and Growth Factor Reviews, vol. 21, no. 5, pp. 331-344, 2010.

[33] M. E. Quintanar-Quintanar, A. Jarillo-Luna, and V. RiveraAguilar, "Immunosuppressive treatment inhibits the development of amebic liver abscesses in hamsters," Medical Science Monitor, vol. 10, no. 9, pp. 317-324, 2004.

[34] A. Asgharpour, C. Gilchrist, D. Baba, S. Hamano, and E. Houpt, "Resistance to intestinal Entamoeba histolytica infection is conferred by innate immunity and $\mathrm{Gr}^{-1} 1+$ cells," Infection and Immunity, vol. 73, no. 8, pp. 4522-4529, 2005.

[35] L. Guo, X. Barroso, S. M. Becker et al., "Protection against intestinal amebiasis by a recombinant vaccine is transferable by $\mathrm{T}$ cells and mediated by gamma interferon," Infection and Immunity, vol. 77, no. 9, pp. 3909-3918, 2009.

[36] E. A. García-Zepeda, M. E.-V. Rojas-López, and P. Ostoa-Saloma, "Regulation of the inflammatory immune response by the cytokine/chemokine network in amoebiasis," Parasite Immunology, vol. 29, no. 12, pp. 679-684, 2007.

[37] W. A. Petri, S. Roy, P. Duggal et al., "Correlation of interferon$\gamma$ production by peripheral blood mononuclear cells with childhood malnutrition and susceptibility to amebiasis," American Journal of Tropical Medicine and Hygiene, vol. 76, no. 2, pp. 340-344, 2007.

[38] I. Bruchhaus, S. Richter, and E. Tannich, "Removal of hydrogen peroxide by the $29 \mathrm{kDa}$ protein of Entamoeba histolytica," The Biochemical Journal, vol. 326, no. 3, pp. 785-789, 1997.

[39] D. M. Meneses-Ruiz, H. Aguilar-Diaz, R. J. Bobes et al., "Protection against amoebic liver abscess in hamster by intramuscular immunization with an Autographa californica
Baculovirus driving the expression of the Gal-lectin LC3 fragment," BioMed Research International, vol. 2015, Article ID 760598, 10 pages, 2015.

[40] C. F. Hung, K. F. Hsu, W. F. Cheng et al., "Enhancement of DNA vaccine potency by linkage of antigen gene to a gene encoding the extracellular domain of Fms-like tyrosine kinase 3-ligand," Cancer Research, vol. 61, no. 3, pp. 1080-1088, 2001.

[41] T. Zhang, P. R. Cieslak, and S. L. Stanley Jr., "Protection of gerbils from amebic liver abscess by immunization with a recombinant Entamoeba histolytica antigen," Infection and Immunity, vol. 62, no. 4, pp. 1166-1170, 1994.

[42] C. Martínez-López, E. Orozco, T. Sánchez, R. M. García-Pérez, F. Hernández-Hernández, and M. A. Rodríguez, "The EhADH112 recombinant polypeptide inhibits cell destruction and liver abscess formation by Entamoeba histolytica trophozoites," Cell Microbiology, vol. 6, no. 4, pp. 367-376, 2004.

[43] B. Jiménez-Delgadillo, P. P. Chaudhuri, L. Baylón-Pacheco, A. López-Monteon, P. Talamás-Rohana, and J. L. RosalesEncina, "Entamoeba histolytica: cDNAs cloned as $30 \mathrm{kDa}$ collagen-binding proteins (CBP) belong to an antioxidant molecule family.: protection of hamsters from amoebic liver abscess by immunization with recombinant CBP," Experimental Parasitology, vol. 108, no. 1-2, pp. 7-17, 2004.

[44] P. P. A. M. Leenaars, M. A. Koedam, P. W. Wester et al., "Assessment of side effects induced by injection of different adjuvant/antigen combinations in rabbits and mice," Laboratory Animals, vol. 32, no. 4, pp. 387-406, 1998.

[45] H. F. Stils Jr., "Adjuvants and antibody production: dispelling the myths associated with Freund's complete and other adjuvants," ILAR Journal, vol. 46, no. 3, pp. 280-293, 2005. 